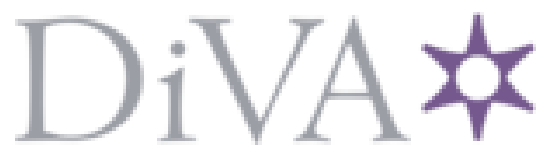

http://www.diva-portal.org

This is the published version of a paper published in IEEE transactions on industrial electronics (1982. Print).

Citation for the original published paper (version of record):

Millinger, J., Wallmark, O., Soulard, J. (2019)

Investigation of Harmonic Losses in a 2-PoleSlotless Permanent-Magnet Motor due to WideBand-Gap Inverter Supply

IEEE transactions on industrial electronics (1982. Print)

https://doi.org/DOI 10.1109/TIE.2019.2939985

Access to the published version may require subscription.

N.B. When citing this work, cite the original published paper.

Permanent link to this version:

http://urn.kb.se/resolve?urn=urn:nbn:se:kth:diva-259945 


\title{
Investigation of Harmonic Losses in a 2-Pole Slotless Permanent-Magnet Motor due to Wide Band-Gap Inverter Supply
}

\author{
Jonas Millinger, Member, IEEE, Oskar Wallmark, Senior Member, IEEE \\ and Juliette Soulard, Member, IEEE
}

\begin{abstract}
The recent emerge of wide band-gap power devices enables higher switching frequencies in electric motor drives. The subsequent possibility for higher efficiency and smaller size requires accurate prediction of harmonic losses in motors. Therefore this paper presents an original analysis of harmonic losses arising in inverter-fed 2-pole slotless permanent-magnet machines with axially segmented ring magnets. The developed three-dimensional time-efficient numerical model is successfully validated under high-speed no-load operation using a silicon-carbide based three-phase inverter and rotors carrying a broad range of magnet segment thicknesses $(3-12.6 \mathrm{~mm})$. The model enables harmonic loss prediction capability (including loss separation) with an accuracy of $15 \%$ over a wide frequency range $(8-120 \mathrm{kHz})$, which is a unique contribution. The sensitivity analysis primarily emphasizes the importance of taking into account the axial segmentation, and secondarily the rotor-shaft magneto-elasticity effects for accurate modeling of harmonic losses. The conducted case-study demonstrates that wide band-gap transistors effectively can contribute to eliminating the need for inductive filters in motor drives.
\end{abstract}

Index Terms-Time-harmonic losses, permanent-magnet machines, wide band-gap semiconductors.

\section{INTRODUCTION}

$\mathbf{I}$ NVERTER-FED slotless permanent-magnet (PM) machines play an important role in high-power density applications such as turbomachinery, compressors, aerospace applications, flywheels and industrial power tools [1]-[4]. The undesired harmonics generated by the inverter PWM process increases the motor losses and thereby reduces the performance [5]. Harmonic losses occur in every conductive part of the machine, but rotor losses are considered more challenging due to the poor heat transfer across the air-gap and winding amalgam of slotless machines [6]. Even though the issue of harmonic losses is not limited to high-speed machines, these machines suffer from a higher proportion of these losses due to their lower inductance [2]. Unfortunately,

Manuscript received November 19, 2018; revised March 4, 2019; April 30, 2019 and July 25, 2019; accepted July 4, 2019. This work was supported by Atlas Copco Industrial Technique AB, Stockholm, Sweden. J. Millinger and O. Wallmark are with the Division of Electric Power and Energy Systems, KTH Royal Institute of Technology, SE10044 Stockholm, Sweden (e-mail:,jonasmil@kth.se; owa@kth.se). $\mathrm{J}$. Soulard is with the Warwick Manufacturing Group, University of Warwick, Coventry CV4 7AL, U.K. (e-mail: j.soulard@warwick.ac.uk). (corresponding author: Jonas Millinger; phone: +46702919187; e-mail: jonasmil@kth.se) the high demands on rotor dynamics limits the possibilities for rotor segmentation [7], necessary for suppression of harmonic eddy-current losses [8]-[10]. Apart from reduced performance, premature bearing failure and rotor demagnetization [11] are challenges to be addressed. The conventional solution is to add a bulky filter to suppress the harmonic currents fed to the motor, resulting in a more complex system.

However, the recent emerge of wide band-gap (WBG) transistors enables significantly higher switching frequencies than their traditional silicon-based counterparts [12]. This may enable a smaller filter, or its complete elimination [13], leading to smaller and less complex systems. Subsequently, a full utilization of WBG-technology in electric drives requires accurate prediction capability of harmonic losses in the motor during the design stage [14]. The topic of harmonic rotor losses in PM-machines has gained considerable attention in recent years (see [15] and its associated references). Aspects that require consideration are:

- Stator structure (slotted or slotless)

- Winding type (helical, concentrated or overlapping)

- Magnet type (interior, surface inset or surface mount)

- Magnet segmentation (circumferential or axial)

While numerical models theoretically provide unlimited accuracy for any given electromagnetic system, analytical models are preferred due to their lower computational burden. Although the vast majority of available analytical models for harmonic rotor losses are aimed towards conventional slotted machinery, several of them emanate from the slotless design due to its simplicity [15]. Slotting and winding distribution effects are often incorporated by adequate distribution of a number of equivalent current sheets [16]. Eddy-current shielding effects can be taken into account by solving the diffusion equation [17]. Subsequently, several powerful models exist for the analytical prediction of harmonic rotor losses in slotless PM machines with ring-shaped magnets of infinite length (see, e.g., [18], [19]).

Even though several papers demonstrate the importance of taking into account magnet length for various PM topologies [20]-[25], no existing harmonic loss model considers ringshaped rotor magnets of finite length. Therefore, this paper presents a unique model for prediction of time-harmonic losses in a 2-pole slotless machine with ring-shaped magnets, taking into account saturation, axial segmentation and eddy-current 
shielding effects. The developed model is experimentally evaluated at no-load for rotors of different magnet segment thickness $(3-12.6 \mathrm{~mm})$ over a wide frequency range $(8-120 \mathrm{kHz})$ using a $\mathrm{SiC}$ based three-phase inverter. The developed model completes the previously developed stator loss model in [13], enabling harmonic loss prediction capability within $15 \%$, including the previously unprecedented separation of harmonic losses in the complete frequency range. Polarization (due to rotor magnets) and non-uniform magnetic field (due to skin effect) in the stator core are considered by deploying the frozen complex permeability method [26], [27].

The paper is organized as follows. The machine is presented in Section II. The FEA model is treated in Section III. The material properties are analysed in Section IV. The experimental method is described in Section V. Results are presented in Section VI. Finally, conclusions are drawn in Section VII.

\section{INVESTIGATED MACHINE}

The investigated machine is used in commercially available handheld industrial nutrunners. The slotless design enables low core losses and thereby high rotational speeds and subsequently high power-density. The absence of slots eliminates cogging torque and provides a practically linear current versus torque relationship [28], with improved position control capability as consequence. The motor cross-section is shown in Figure 1. The innermost layer represents the solid steel

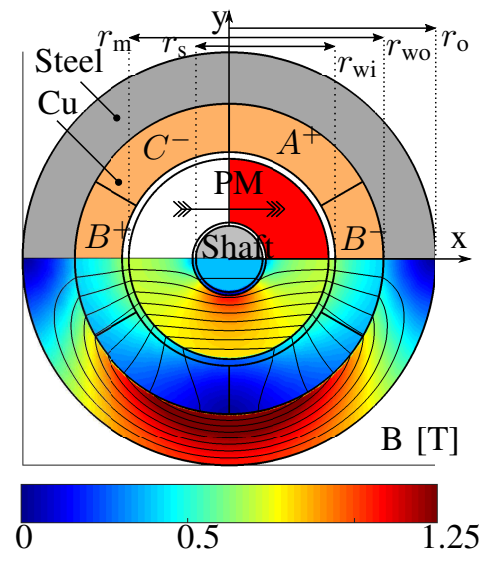

Fig. 1. Axial cross-section of the studied motor $\left(i_{d, q}=0\right.$ A, i.e., field lines only due to PMs).

shaft. The shaft carries an axially segmented stack of $\mathrm{NdFeB}$ ring magnets with parallel magnetization. The rotor and stator are separated by a $0.5 \mathrm{~mm}$ air gap. The stator comprises an axially laminated stator yoke of electrical steel, internally carrying an overlapping three-phase copper winding fixed by an impregnation varnish. The laminations are of $0.2 \mathrm{~mm}$ thickness and are supported by 8 axially oriented welding seams. The stator steel [13], [29] contains $3 \%$ silicon and $0.4 \%$ aluminum per weight unit. The motor phases are Yconnected, and the Y-point is buried inside one of the endwindings. Key motor data is summarized in Table I. The axial cross-section is shown in Fig. 2a. Perfect insulation is assumed between the magnet segments and the shaft. Thin
TABLE I

MOTOR DATA

\begin{tabular}{ccc}
\hline \hline Quantity & Symbol & Value \\
\hline Peak torque & $\hat{T}$ & $1.2 \mathrm{Nm}$ \\
Max speed & $\hat{\omega}$ & $30 \mathrm{krpm}$ \\
DC bus voltage & $U_{\mathrm{DC}}$ & $325 \mathrm{~V}$ \\
Motor active length & $L_{a}$ & $64.5 \mathrm{~mm}$ \\
Stator outer radius & $r_{o}$ & $15.5 \mathrm{~mm}$ \\
Stator yoke inner radius & $r_{w o}$ & $11.6 \mathrm{~mm}$ \\
Magnet radius & $r_{m}$ & $7.5 \mathrm{~mm}$ \\
Shaft radius & $r_{s}$ & $2.5 \mathrm{~mm}$ \\
Magnet remanent flux density & $B_{r, \text { magnet }}$ & $1.3 \mathrm{~T}$ \\
Shaft resistivity [30] & $\rho_{\text {shaft }}$ & $0.47 \mu \Omega \mathrm{m}$ \\
\hline \hline
\end{tabular}

electrical insulation sheets ensure electrical insulation between the magnets. The resulting main rotor eddy currents (due to time-harmonics) are schematically illustrated in Fig. 2 b.

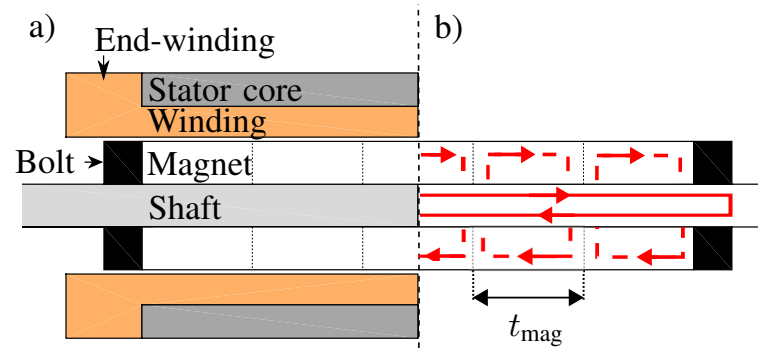

Fig. 2. Motor radial cross-section: a) geometry; b) eddy-current scetch.

The typical nutrunner load-profile (see Fig. 3) can be divided into a rundown, followed by a tightening. The rundown

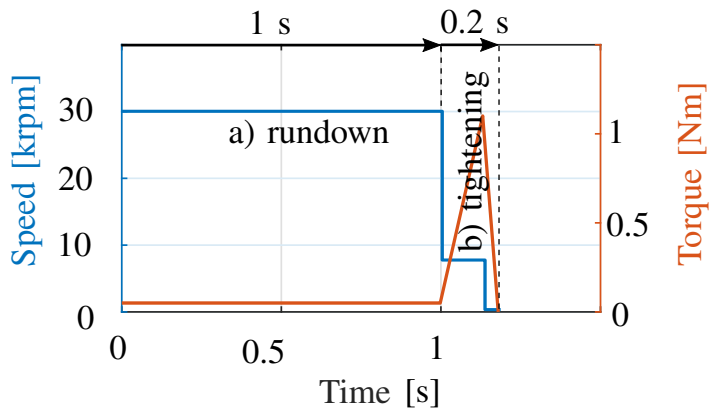

Fig. 3. The typical load profile: a) rundown; b) tightening.

is represented by high speed and low torque, while the tightening is characterized by low speed and high torque. The high dynamic demands of the application requires inverter connection and rapid speed control. Tightening losses are dominated by copper conduction losses while rundown losses mainly consist of magnetic losses, such as eddy-current and iron losses [31]. Small signal simulations of the investigated motor show that the inductances decrease less than $2 \%$ at full load in the complete frequency range (due to the large effective air-gap [13]). The simulated $d$ and $q$-axis inductances at $50 \mathrm{kHz}$, using a rotor carrying magnet segments of $6.3 \mathrm{~mm}$ thickness, are displayed in Fig. 4 until full load. Subsequently, harmonic losses during the tightening stage are expected to behave similarly to the ones during no-load. The motor no- 


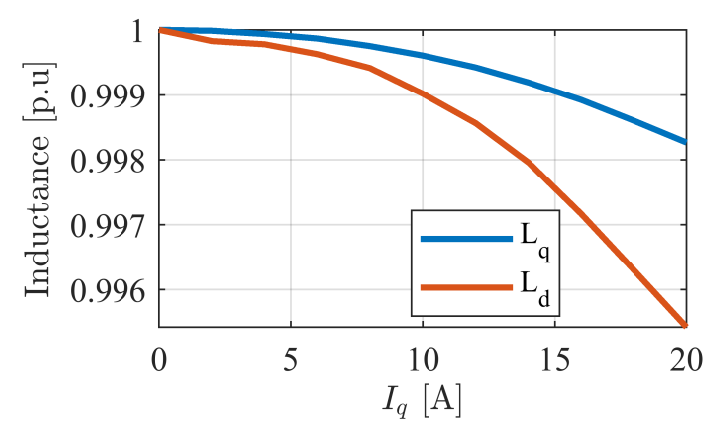

Fig. 4. Influence of $q$-axis current on small signal inductance (at $50 \mathrm{kHz}$ ) using a rotor carrying $6.3 \mathrm{~mm}$ magnet segments.

load losses at inverter supply were measured over a broad speed range in [32]. Using the loss experimental data, cycle losses were estimated. The results show that around $95 \%$ of the harmonic losses are generated during rundown, mainly associated to the high-speed operation (i.e., high modulation index [5]) and long time duration.

Utilization of wide band-gap devices leads to steeper voltage slopes, which may increase the winding insulation stress. While voltage overshoots at the motor terminals can be mitigated by using short cables, also the increasingly non-uniform winding inter-turn voltage distribution requires consideration [33]. For a $50 \mathrm{~ns}$ rise-time, the latter effect is insignificant in the considered machine [34]. However, faster rise-times may cause complications but is out of the scope for this paper.

Improved motor control techniques enable higher tightening speeds, with reduced tightening losses as consequence. Therefore, minimization of rundown losses is gaining emphasis for improved nutrunner performance. The rundown losses can be approximated by the no-load losses [13]. The no-load losses are comprised of fundamental $\left(P_{0}\right)$ and harmonic losses $\left(P_{h}\right)$ according to $P_{\text {no-load }}=P_{0}+P_{h}$. While the fundamental losses are independent of the converter, the harmonic ones depend on both converter topology and switching frequency. The studied 2-level PWM process uses a phase-advanced, symmetrically sampled reference with a triangular carrier and 1/6 third harmonic injection. The phase to neutral voltages $\left\{v_{a z}, v_{b z}, v_{c z}\right\}$ in a symmetric three-phase system for such a PWM scheme can be expressed as [5]:

$$
\begin{aligned}
v_{x z} & =\overbrace{V_{0} \cos \left(\omega_{0} t+\varphi_{0 x}\right)}^{\text {Fundamental component }} \\
& +\sum_{n=1}^{\infty} \sum_{m=-\infty}^{\infty} \underbrace{V_{h} \sin \left([m+n] \frac{\pi}{2}\right) \cos \left(\left[m \omega_{0} n+\omega_{\mathrm{sw}}\right] t+\varphi_{h x}\right)}_{\text {Carrier sideband harmonics }}
\end{aligned}
$$

where $V_{0}$ and $V_{h}$ are the fundamental and harmonic voltage amplitudes, respectively. Here, $\omega_{0}$ is the fundamental angular speed and $\omega_{\mathrm{sw}}$ is the angular speed of the carrier waveform. The carrier index $n$ is a positive integer while the fundamental index $m$ is an integer. $\varphi_{0 x}$ and $\varphi_{h x}$ are the offset phasors for the fundamental and the carrier waveform, respectively. The undesired harmonic voltage components $V_{h}$ generate currents according to $I_{h}=\frac{V_{h}}{j \omega L(\omega)}$ (where $L(\omega)$ is the frequency dependent machine inductance). Unfortunately, the resulting harmonic currents only contribute to losses, with reduced machine performance as consequence. Assuming phase $a$ as reference phasor, $\varphi_{0 x}$ and $\varphi_{h x}$ for all phases can be expressed according to Table II.

TABLE II

PHASE SHIFTS

\begin{tabular}{c|c|c|c} 
& $\mathbf{a}$ & $\mathbf{b}$ & $\mathbf{c}$ \\
\hline$\varphi_{0 x}$ & 0 & $\frac{2 \pi}{3}$ & $-\frac{2 \pi}{3}$ \\
\hline$\varphi_{h x}$ & 0 & $\frac{2 \pi}{3} m$ & $-\frac{2 \pi}{3} m$
\end{tabular}

Using Eq. (1), it can be demonstrated that the following combinations of $n$ and $m$ are eliminated [5]:

- Harmonics with even combinations of $m \pm n$ are eliminated within each phase leg by the $\sin \left([m+n] \frac{\pi}{2}\right)$ factor.

- Triplen sideband harmonic currents $(m=0,3,6 \ldots)$ eliminate due to common mode (see Table II).

Furthermore, sidebands of order $m>7$ are insignificant and can therefore neglected [5]. Subsequently, harmonics appear at sideband frequencies $f_{h}$ around multiples of the switching frequency $f_{s w}$ according to:

$$
f_{h}=f_{\{n, m\}}=n \cdot f_{s w}+m \cdot f_{0}
$$

where $f_{0}$ is the fundamental frequency. Significant harmonics appear at the combinations of $n$ and $m$ summarized in Table III.

TABLE III

HARMONIC SIDEBAND LOCATIONS

\begin{tabular}{c|c} 
odd $n$ & even $n$ \\
\hline$m=\{-4,-2,2,4\}$ & $m=\{-5,-1,1,5\}$
\end{tabular}

Due to the rapid decay of harmonic content beyond the second multiple of the switching frequency, this study has been limited to studying the first three harmonic sideband groups, $n=\{1,2,3\}$, using a conventional 2-level three-phase converter. Fig. 5 shows the measured phase-to-neutral voltage and current waveforms using 8 and $20 \mathrm{kHz}$ under $30 \mathrm{krpm}$ noload operation. The resulting current spectrum for the $8 \mathrm{kHz}$ case, considering the first 3 sideband groups, is shown in Fig. 6. To simplify the calculations and reduce computational time, the RMS-values of each sideband group $I_{\text {eq }}$ (see Fig. 6) are used as FEA input. These are computed according to:

$$
\begin{gathered}
\text { odd } n: I_{\text {eq }}=\sqrt{\sum_{m=\{-4,-2,2,4\}} I_{\{n, m\}}^{2}} \\
\text { even } n: I_{\text {eq }}=\sqrt{\sum_{m=\{-5,-1,1,5\}} I_{\{n, m\}}^{2}} .
\end{gathered}
$$

A typical silicon-based inverter uses a switching frequency in the range 5-15 kHz while its WBG-based counterpart could use a switching frequency of $20-100 \mathrm{kHz}$. In order to cover both technologies, the investigated frequency range is chosen to $8-120 \mathrm{kHz}$ in this study. 


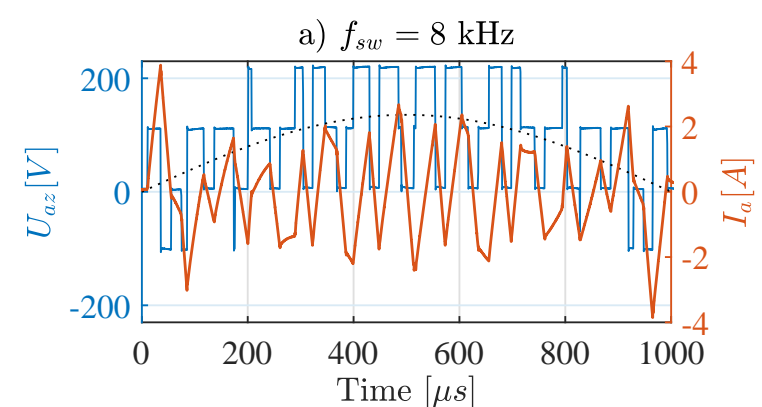

b) $f_{s w}=20 \mathrm{kHz}$

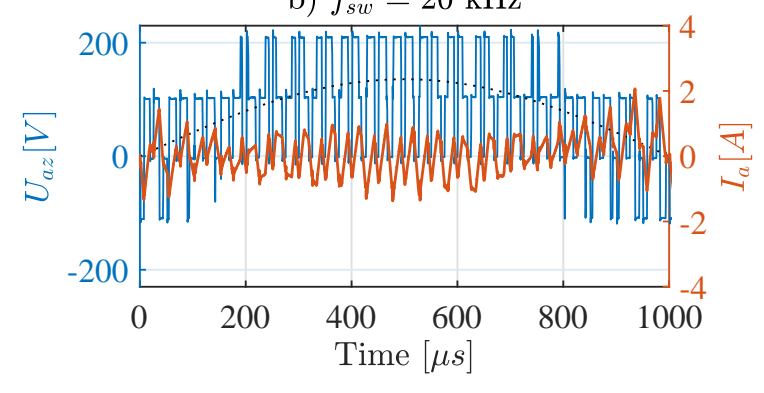

Fig. 5. Measured phase-to-neutral voltage and current at $f_{0}=500 \mathrm{~Hz}$ and no-load, using a) $f_{\mathrm{sw}}=8 \mathrm{kHz}$; b) $f_{\mathrm{sw}}=20 \mathrm{kHz}$.

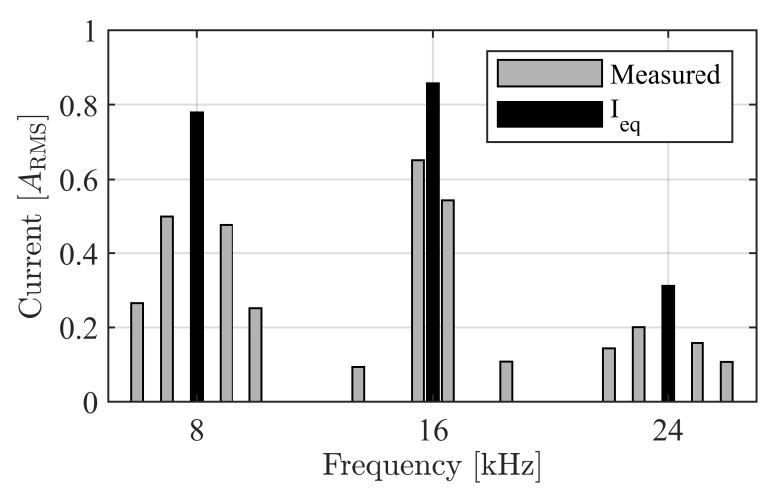

Fig. 6. Harmonic phase current spectrum at $f_{0}=500 \mathrm{~Hz}$ ) no-load, using $f_{\mathrm{sw}}=8 \mathrm{kHz}$.

\section{3D FEA MODEL}

Previous studies have shown an almost perfect decoupling of the $d$ and $q$-axis for the machine under consideration [35], as well as a near linear flux-linkage to current relationship due to its large magnetic air-gap [13]. Therefore, a 3D model with pulsating input and locked-rotor has been developed. The proposed analysis process is described in Fig. 7 and illustrated in Fig. 8. The pulsating input enables quarter symmetry reduction of the numerical model with significant improvement of the computational efficiency [35]. The magnetization of the stator yoke due to rotor magnets and the non-uniform flux density (due to skin effect arising in the laminations at high frequencies) are taken into account by using the complex frozen permeability method [26], [36].

First, flux density distribution due to the permanent magnets is determined (Fig. 8a) by a DC-simulation. Next, the minorloop frozen-permeability map is determined (Fig. 8b) using material data from [13]. Finally, the harmonic flux density distribution due to a pulsating input current according to the

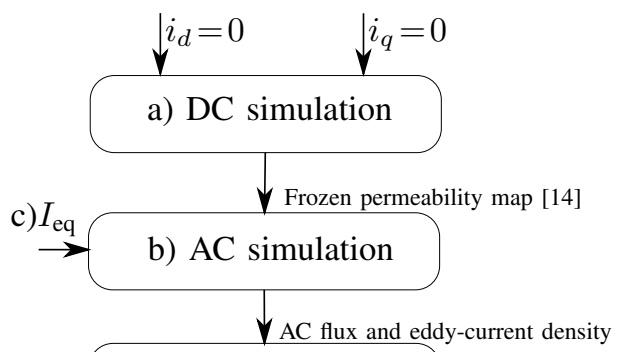

d) Loss analysis

$$
\downarrow_{(\text {Eq. 6) }} \quad \downarrow_{(\text {Eq. }} P_{\text {rotor }}
$$

Fig. 7. Flowchart of the analysis process

phase-to-phase connection in Fig. 8e is determined via an ACsimulation (see Fig. 8d). The FEA model is shown in Fig. 9.

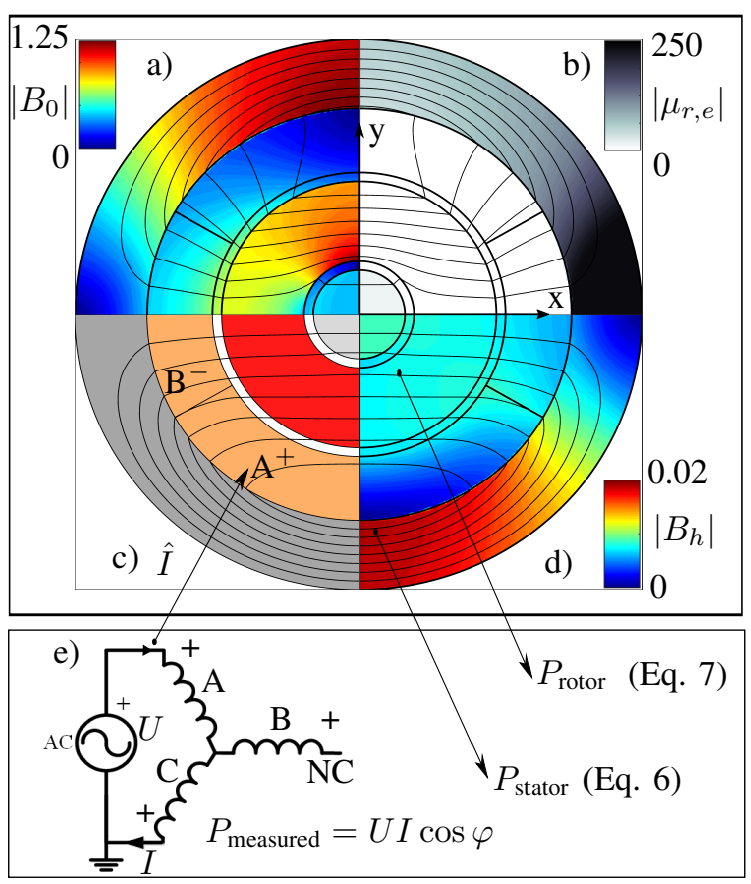

Fig. 8. Model description: a) DC-bias flux; b) Minor-loop frozen permeability map; c) Geometry; d) Harmonic flux density distribution for $\hat{I}=1 \mathrm{~A} ; \mathrm{e})$ pulsating input connection.

The applied boundary conditions, illustrated in Fig. 10, enable a reduction to $1 / 8$ of the original (due to symmetries). The mesh size is set to one third of the skin depth in the magnet and shaft surface. The number of total mesh elements and resulting simulation times for two cases of material settings (see Table V) are summarized in Table IV using a $3.4 \mathrm{GHz}$ CPU with 6 cores and 512 GB RAM.

\section{A. Power losses}

The harmonic fields give uprise to eddy-currents in all conductive parts of the motor, which in turn generate harmonic power losses $\left(P_{h}\right)$ in the stator $\left(P_{\text {stator }}\right)$ and rotor $\left(P_{\text {rotor }}\right)$ according to:

$$
P_{\mathrm{h}}=P_{\text {stator }}+P_{\text {rotor }}
$$




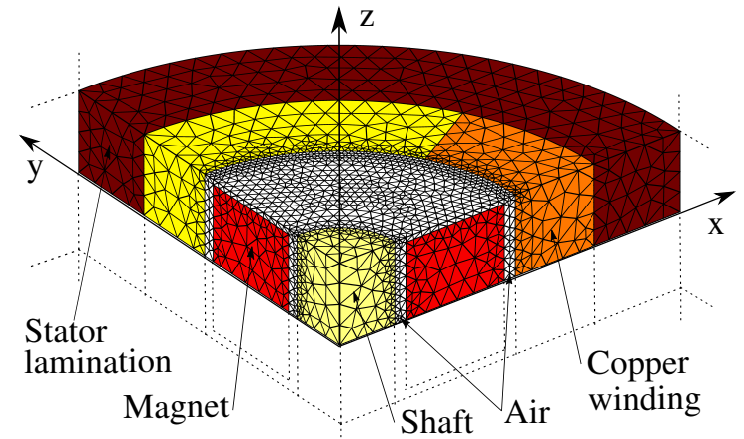

Fig. 9. 3D FEA model.

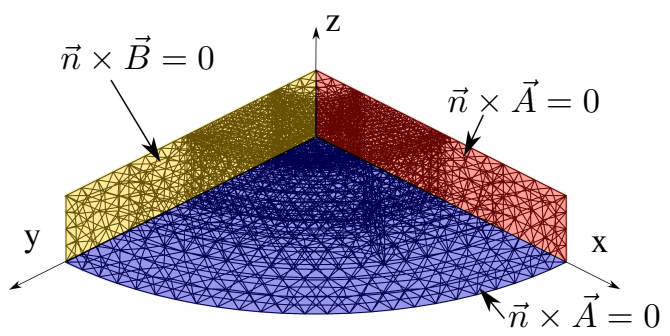

Fig. 10. 3D FEA model boundary conditions.

1) Stator losses: The stator losses comprise of stator lamination iron losses $P_{\text {lam }}$ and copper winding losses $P_{\mathrm{w}}$ [13]:

$$
P_{\text {stator }}=\underbrace{C(f) B_{\text {lam }}^{2} f^{2}}_{P_{\text {lam }}}+\underbrace{k_{\text {skin }} R_{\mathrm{DC}} I^{2}+k_{\mathrm{prox}} H_{w}^{2}}_{P_{\mathrm{w}}}
$$

where $C(f)$ is the empirically determined frequency dependent steinmetz coefficient [13], $B_{\text {lam }}$ is the lamination RMS flux density and $f$ is the frequency. $I$ is the RMS value of the stator current and $H_{\mathrm{w}}$ is the winding region RMS magnetic field. $R_{\mathrm{DC}}$ is the stator winding DC-resistance. Here, $k_{\text {skin }}$ and $k_{\text {prox }}$ are the skin and proximity effect factors [13], respectively.

2) Rotor losses: The rotor eddy-currents are simulated with 3D FEA for accurate modeling of the magnet segmentation. The resulting low-frequency rotor eddy-current pattern (i.e., no skin effect present) is illustrated in Fig. 11. As can be seen, the shaft eddy-currents are solely axially oriented, while the currents in the magnets exhibit the classical loop-shape.

The rotor losses, constituting the shaft $\left(P_{\text {shaft }}\right)$ and magnet

TABLE IV

TOTAL SIMULATION TIME AT $100 \mathrm{KHz}$

\begin{tabular}{c|c|c|c}
\hline Quantity & $\mathbf{3} \mathbf{~ m m}$ & $\mathbf{6 . 3} \mathbf{~ m m}$ & $\mathbf{1 2 . 6} \mathbf{~ m m}$ \\
\hline \hline Mesh elements & 15685 & 27043 & 47107 \\
Sim. time (case 1) & $48 \mathrm{~s}$ & $90 \mathrm{~s}$ & $112 \mathrm{~s}$ \\
Sim. time (case 3) & $106 \mathrm{~s}$ & $164 \mathrm{~s}$ & $285 \mathrm{~s}$
\end{tabular}

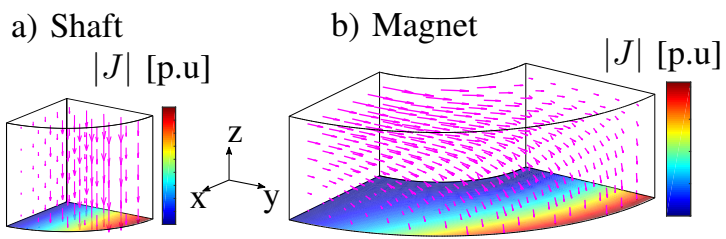

Fig. 11. Low frequency eddy current patterns and normalized current densities using puslating input for the a) shaft; b) permanent magnets.

losses $\left(P_{\text {mag }}\right)$, are computed according to:

$$
P_{\text {rotor }}=\underbrace{\rho_{\text {shaft }} \iiint_{V_{\text {shaft }}} J^{2} d V}_{P_{\text {shaft }}}+\underbrace{\rho_{\text {mag }} \iiint_{V_{\text {mag }}} J^{2} d V}_{P_{\text {magnet }}}
$$

where $J$ is the current density, $V$ denominates volume and $\rho$ is the material resistivity.

\section{B. Rotating to pulsating current input}

Modeling of harmonic losses with rotating input requires conversion of the rotating current into a pulsating one. The conversion is only valid under the assumption of linear material properties. A pulsating current $\boldsymbol{i}_{\text {puls }}$ according to the connection in Fig. 8 can be expressed in $\alpha \beta$-components according to:

$$
\boldsymbol{i}_{\text {puls }}=\left[\begin{array}{c}
i_{a} \\
i_{b} \\
i_{c}
\end{array}\right]=\left[\begin{array}{c}
\hat{I} \cos (\omega t) \\
0 \\
-\hat{I} \cos (\omega t)
\end{array}\right] \rightarrow\left[\begin{array}{c}
i_{\alpha} \\
i_{\beta}
\end{array}\right]_{\text {puls }}=\left[\begin{array}{c}
\hat{I} \\
\frac{-\hat{I}}{\sqrt{3}}
\end{array}\right] \cos (\omega t)
$$

A symmetric three-phase current with the same input amplitude $\hat{I}$ can be expressed in $\alpha \beta$-components as:

$$
\boldsymbol{i}_{\mathrm{rot}}=\left[\begin{array}{c}
i_{a} \\
i_{b} \\
i_{c}
\end{array}\right]=\left[\begin{array}{c}
\hat{I} \cos (\omega t) \\
\hat{I} \cos \left(\omega t+\frac{2 \pi}{3}\right) \\
\hat{I} \cos \left(\omega t-\frac{2 \pi}{3}\right)
\end{array}\right] \rightarrow\left[\begin{array}{c}
i_{\alpha} \\
i_{\beta}
\end{array}\right]_{\mathrm{rot}}=\left[\begin{array}{c}
\hat{I} \cos (\omega t) \\
\hat{I} \sin (\omega t)
\end{array}\right]
$$

The resulting current vectors for the inputs suggested in equations (8)-(9) are illustrated in Fig. 12. The RMS relation of pulsating and rotating current inputs can be expressed:

$$
\frac{\left|\boldsymbol{i}_{\mathrm{rot}, \mathrm{RMS}}\right|}{\left|\boldsymbol{i}_{\mathrm{puls}, \mathrm{RMS}}\right|}=\sqrt{\frac{3}{2}}
$$

enabling the proposed pulsating input approach for modeling of harmonic losses (under the assumption of linear material properties). Subsequently, the equivalent current component of each sideband group $I_{\text {eq }}$, using equations (3)-(4), can be inserted in the proposed FEA model using $I_{\text {puls }}=\sqrt{\frac{3}{2}} I_{\mathrm{eq}}$.

\section{MATERIAL PROPERTIES}

This section details the investigations run to determine important material properties influence in the simulation model. The influence of the shaft material is investigated in Section IV-A. Next, the influence of magnet material and stator yoke properties are analyzed in Section IV-B. 


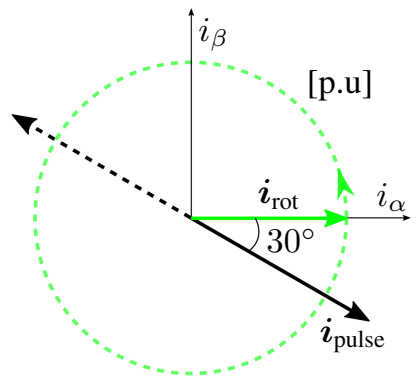

Fig. 12. Comparison of pulsating and rotating current input.

\section{A. Shaft material}

As reported in [35], the shaft relative permeability has a significant impact on total rotor losses. Therefore, the shaft material minor loop behavior was characterized using a Lakeshore 480 Fluxmeter. The ring-core sample and the results are shown in Fig. 13, demonstrating approximately linear (and reversible) minor loops with permeabilities in the region $\left\{20<\mu_{\mathrm{r} \text {,shaft }}<40\right\}$ throughout the complete DC-bias range. However, the massive tensile stress $(\sigma>500 \mathrm{MPa})$

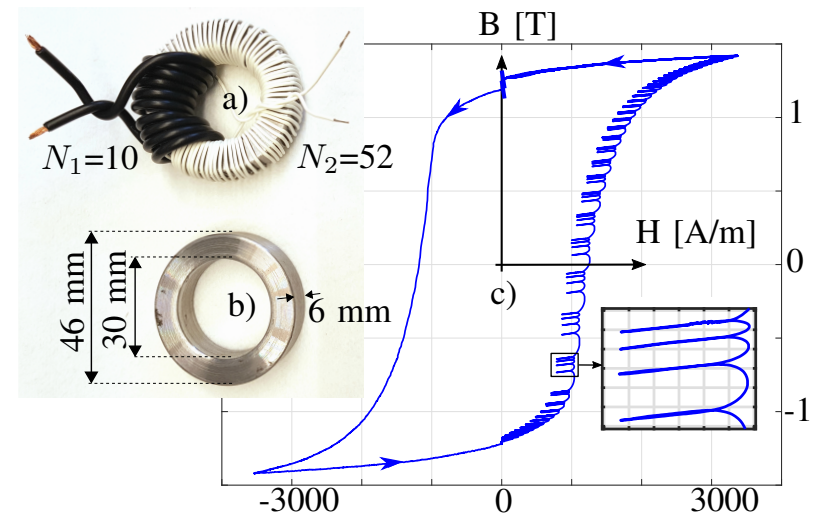

Fig. 13. Shaft material characterization: $a-b)$ ring-core sample c) results.

in the axial direction of the rotor shaft aligns the magnetic domains in the parallel direction of force [37], subsequently causing a demagnetization in the perpendicular direction [37], [38] (in which the harmonic field is predominantly oriented). The influence of different rotor shaft permeability settings on power losses (for a rotor carrying $3 \mathrm{~mm}$ magnets) are shown in Fig. 14. The overall best resemblance, considering the whole frequency range, is achieved for shaft permeabilities within $\mu_{\mathrm{r}, \text { haft }}=1-2$, indicating almost complete demagnetization in the radial direction of the shaft.

\section{B. Magnet material and stator yoke}

The currently available analytical models for prediction of harmonic rotor losses in slotless PMSMs [19], [39], [40] all make the following assumptions:

(a) Axial segmentation of magnets is neglected

(b) Stator core material is linear.

(c) Isotropic magnet permeability and resistivity

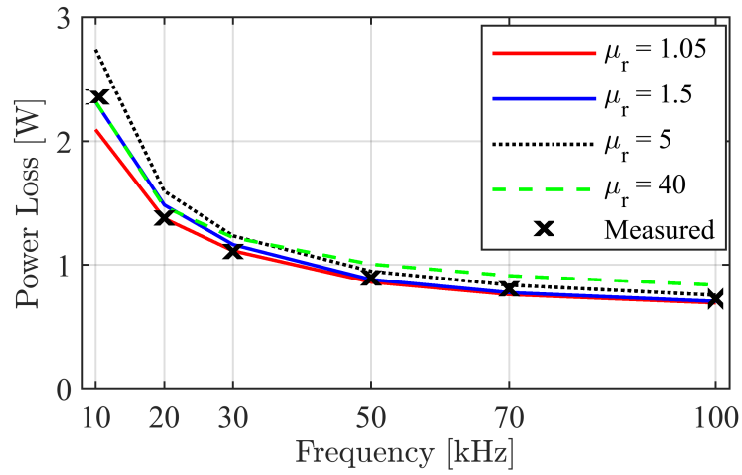

Fig. 14. Influence of the shaft permeability $\mu_{\mathrm{r} \text {,shaft }}$ on modeled losses for a rotor carrying magnet segments of $3 \mathrm{~mm}$ thickness.

The influence of such assumptions are investigated in the following. Case 1 assumes linear and isotropic material properties. Case 2 takes into account magnetization of the stator core (using the frozen permeability method [13]). Finally, Case 3 takes into account polarization of the stator core as well as anisotropic magnet properties according to [41], [42].

TABLE V

FEA MODEL SETTINGS

\begin{tabular}{c|c|c|c|c|c} 
& $\mu_{\mathrm{r}, \mathrm{lam}}$ & $\rho_{\mathrm{mag} \|}$ & $\rho_{\mathrm{mag} \perp}$ & $\mu_{\mathrm{r}, \mathrm{mag} \|}$ & $\mu_{\mathrm{r}, \mathrm{mag} \perp}$ \\
\hline Case 1 & 1000 & \multicolumn{2}{|c|}{$1.5 \mu \Omega \mathrm{m}$} & \multicolumn{2}{|c}{1.05} \\
\hline Case 2 & $\mu_{r, e}$ & \multicolumn{2}{|c|}{$1.5 \mu \Omega \mathrm{m}$} & \multicolumn{2}{|c}{1.05} \\
\hline Case 3 & $\mu_{r, e}$ & $1.5 \mu \Omega \mathrm{m}$ & $1.3 \mu \Omega \mathrm{m}$ & 1.03 & 1.12
\end{tabular}

Assumption (a) is evaluated in Fig 15a by comparing 2D results with measured ones (for a rotor with $3 \mathrm{~mm}$ magnet segment thickness) using linear, isotropic material settings defined by Case 1 in Table V. The $2 \mathrm{D}$ results overestimate losses with up to $240 \%$ at $(10 \mathrm{kHz})$, which paramounts the significance of taking into account axial segmentation.

However, all three configurations listed in Table $\mathrm{V}$ enable loss prediction capability within $10 \%$ when modeled in 3D. Furthermore, the conducted sensitivity analysis shows that the stator yoke polarization and magnet anisotropy have negligible impact on simulation results, but clearly emphasizes the need to accurately take into account the axial segmentation of the magnets as well as magneto-elasticity effects on the shaft. While the frozen-permeability method improves the model predictions for many slotted machine types, it does not make a significant difference for the investigated slotless machine due to the large effective air-gap [13]. All simulations hereafter are conducted in 3D using Case 3 settings.

\section{METHOD}

This section describes the experimental test procedures conducted in this paper. Section V-A describes the locked rotor tests with pulsating input, conducted as a first validation step. Section V-B finally describes the no-load tests with inverter supply. 
a)

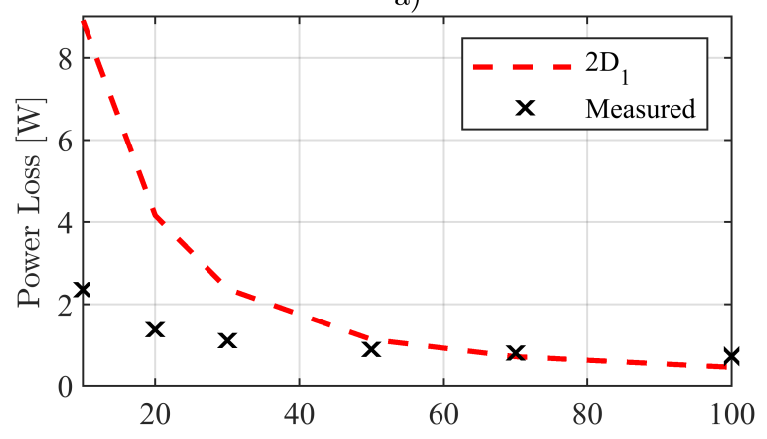

b)

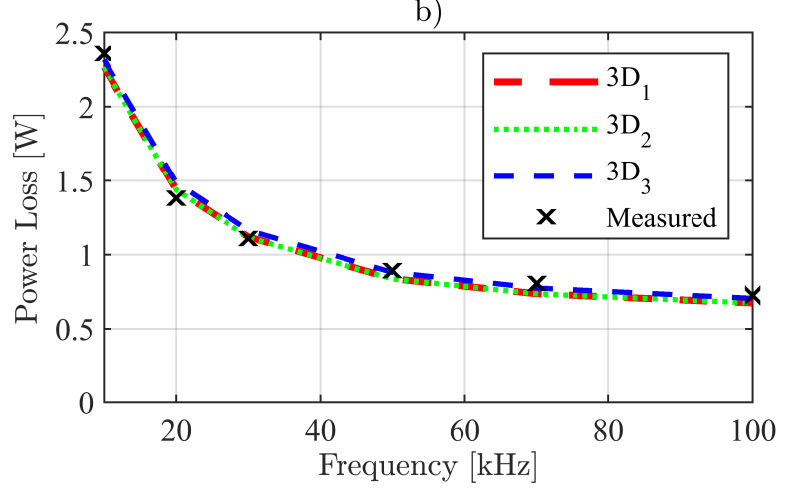

Fig. 15. Influence of material settings on model accuracy for $t_{\mathrm{mag}}=3 \mathrm{~mm}$ : a) 2D simulation (Case 1) compared to measured losses; b) $3 \mathrm{D}$ simulations (Cases 1-3) compared to measured losses.

\section{A. Locked-Rotor Test}

The locked rotor tests were conducted by exciting the slotless stator (depicted in Fig. 17d) with a sinusoidal voltage according to the connection in Fig. 8e. The voltage was achieved by cascading a waveform generator with a linear power amplifier. The voltage and current data were acquired using a high bandwidth power meter, using the methodology described in [13]. The average result of 5 consecutive periods was determined using a sampling frequency of $2.5 \mathrm{Gs} / \mathrm{s}$. Any thermal effect on power loss variation was minimized by conducting short measurements $(<5 \mathrm{~s})$ at room temperature $\left(23-25^{\circ} \mathrm{C}\right)$.

\section{B. No-Load Test}

The two-wattmeter method was deployed for power measurement. Exactly 500 consecutive fundamental periods were recorded using a sampling frequency of $25 \mathrm{Ms} / \mathrm{s}$. The measured currents and voltages of each fundamental period were transformed into Fourier domain. Next, the obtained current spectrum was phase-compensated using current-probe characterization data according to [13]. Finally, the active power spectrum was computed. Similar to the locked-rotor case, the thermal impact on power losses was minimized by conducting short measurements at room temperature. The equipment involved is listed in Table VI.
TABLE VI

EQUIPMENT

\begin{tabular}{ll}
\hline \hline \multicolumn{1}{c}{ Equipment type } & \multicolumn{1}{c}{ Model } \\
\hline Waveform Generator & Agilent 33500B \\
Power Amplifier & AE Techtron 7224 \\
Power Meter & Lecroy MDA 803 \\
Voltage probe & HVD 3106 \\
Current probe & CP031 \\
Temperature logger & Agilent 34970A \\
Resistance meter & Fluke 8842A \\
\hline \hline
\end{tabular}

\section{EXPERIMENTAL RESULTS}

This section is divided into the locked-rotor tests (Section VI-A), and the no-load tests (Section VI-B).

\section{A. Locked rotor tests}

The power loss measurements were conducted in the two rotor positions A-B illustrated in Fig. 16, corresponding to a pure $q$-axis and $d$-axis harmonic field, respectively. Three
a) Position $\mathrm{A}$
b) Position B

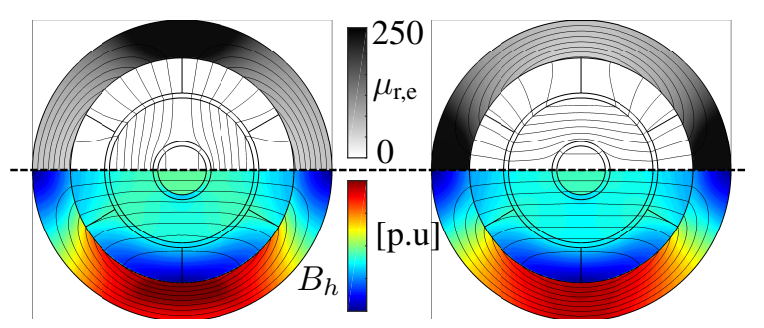

Fig. 16. Evaluated positions: a) $q$-axis; b) $d$-axis pulsating flux.

different rotors were evaluated (see Fig. 17), carrying 12.6; 6.3 and $3 \mathrm{~mm}$ magnet segments, respectively. The rotors were radially centered inside the stator using a few layers of paper tape at each end of the magnet stack. Alignment of the rotor in the $d$-axis position was achieved by applying a $4 \mathrm{~A}$ DC current pulse. The subsequent $q$-axis alignment was made by mechanically displacing the rotor with $\left(90^{\circ}\right)$. Average losses
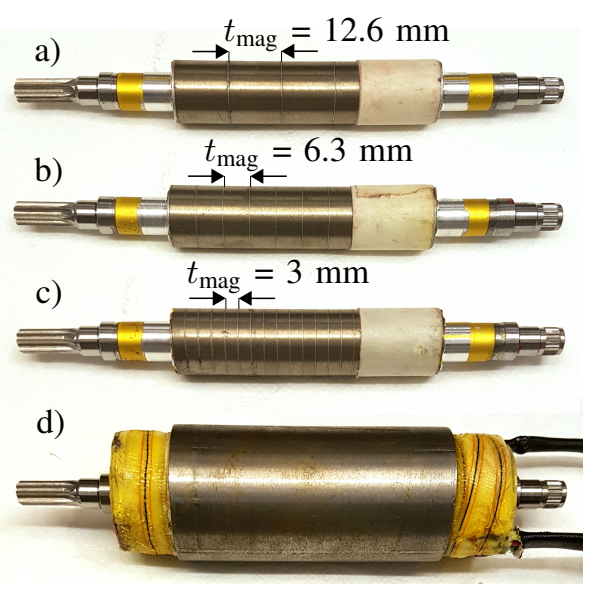

Fig. 17. Investigated rotors equipped with a) $12.6 \mathrm{~mm}$ magnets; b) 6.3 $\mathrm{mm}$ magnets; c) $3 \mathrm{~mm}$ magnets. d) Rotor inside the stator. 
for the two rotor positions are presented in Fig 18. Note that the error-bars in this case show the max and min levels of the two positions (i.e., not accuracy). As can be seen, the model exhibits loss prediction capability within $10 \%$ for $f \geq 20 \mathrm{kHz}$ regardless of rotor. The developed model shows that rotor
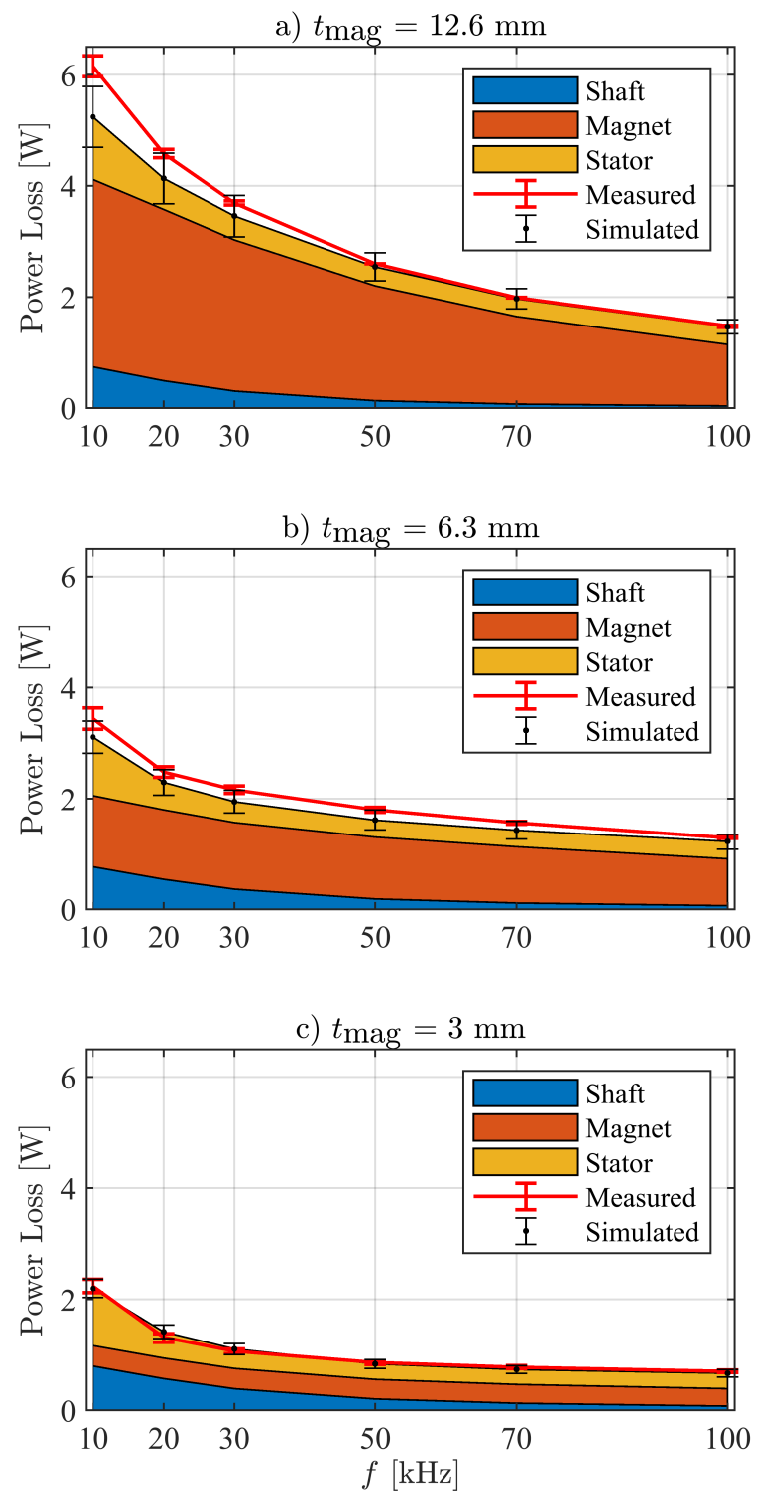

Fig. 18. Average losses of positions A-B. Error bars show the maximum and minimum losses for the two positions.

losses constitute $60-80 \%$ of the total harmonic losses. While the magnet losses are almost independent of the frequency for the $3 \mathrm{~mm}$ magnet case, the $12.6 \mathrm{~mm}$ magnet losses are more than twice as high at $10 \mathrm{kHz}$ compared to $100 \mathrm{kHz}$. The drop in magnet losses is explained by an increasing eddy-current shielding effect with frequency (Fig. 19), reducing the total levels of harmonic flux. An underestimation of losses can be observed for frequencies below $30 \mathrm{kHz}$ in the $12.6 \mathrm{~mm}$ magnet case. One possible reason is an increased level of leakage field outside the active length for thicker magnets (due to lower effective magnet resistivity and thus higher levels of eddycurrent reflection in the magnets), which is not taken into account by the model.

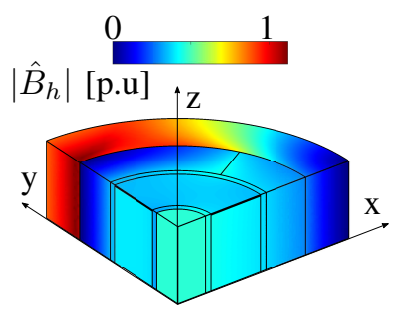

a) $1 \mathrm{kHz}$

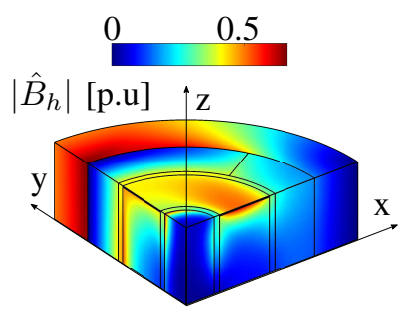

b) $100 \mathrm{kHz}$
Fig. 19. Normalized harmonic flux density distribution in position A for $12.6 \mathrm{~mm}$ magnet at a) $1 \mathrm{kHz}$; b) $100 \mathrm{kHz}$.

\section{B. No-load tests}

In this section, the validity of the proposed model has been evaluated under rotating input. Two different rotors were evaluated under no-load operation, equipped with magnets of $3 \mathrm{~mm}$ and $4.5 \mathrm{~mm}$ thickness, respectively. The machine was

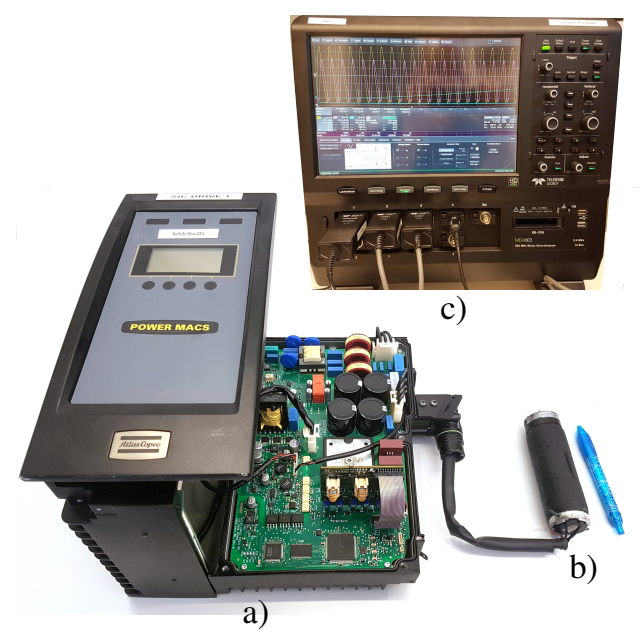

Fig. 20. Investigated motor drive: a) Inverter; b) Motor; c) Power meter.

fed by a three-phase inverter (see Fig. 20) equipped with two parallel-connected SiC-MOSFETs (C2M0025120D) in each phase-leg. A switching frequency of $8 ; 20$ and $40 \mathrm{kHz}$ is used. The obtained power loss spectrums at 20 and $40 \mathrm{kHz}$ switching frequency are shown in Fig. 21. As can be seen, the loss prediction capability is within $15 \%$ for all examined harmonic components. The difference is mainly explained by the losses in the metallic parts, such as the rotor parts outside the active length which are not considered. The superposition of harmonic loss components in soft magnetic materials such as the stator yoke and rotor shaft may add to the discrepancy. However, the results still justify the superposition approach for fast, yet sufficiently accurate modeling of time-harmonic losses in the considered machine. The total harmonic losses for a set of selected cases at $30 \mathrm{krpm}$ and no-load are reported in 
Fig. 22. The results show that harmonic losses at unfiltered conditions (unfilt.), i.e., without using the inductive motor filter, can be reduced with two thirds (from $27 \mathrm{~W}$ to $9 \mathrm{~W}$ ) by using $3 \mathrm{~mm}$ instead of $4.5 \mathrm{~mm}$ magnets and adopting a switching frequency of $40 \mathrm{kHz}$ instead of $8 \mathrm{kHz}$. As a reference, the losses under nominal, filtered (filt.) conditions, are also shown.

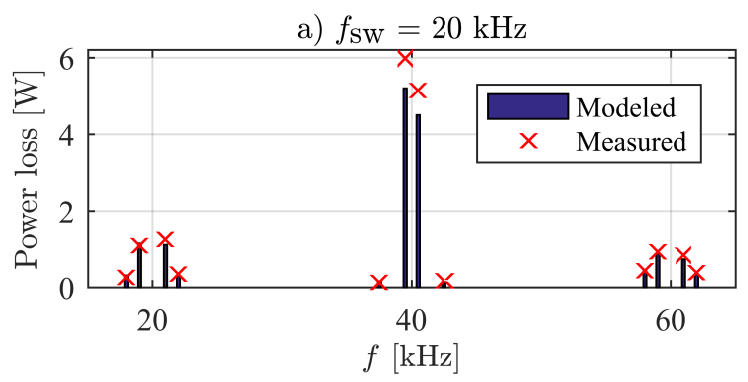

b) $f_{\mathrm{SW}}=40 \mathrm{kHz}$

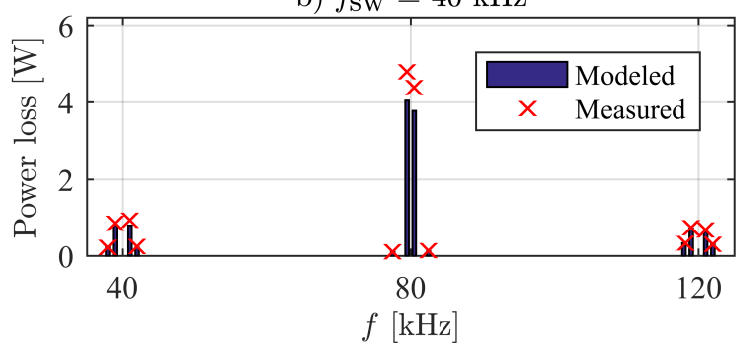

Fig. 21. No-load harmonic power spectrums at a) $f_{\mathrm{sw}}=20 \mathrm{kHz}$; b) $f_{\mathrm{sw}}=40 \mathrm{kHz}$ for rotor carrying $4.5 \mathrm{~mm}$ magnets.
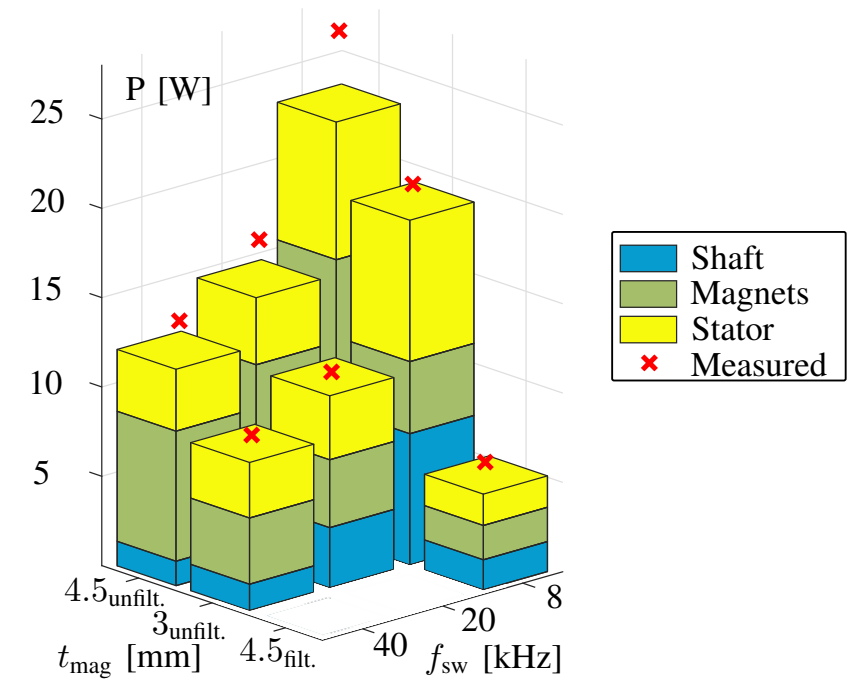

Fig. 22. Harmonic no-load losses

\section{CONCLUSION}

This paper presents a complete analysis of harmonic losses arising in inverter-fed 2-pole slotless permanent-magnet machines with axially segmented ring magnets. The developed three-dimensional time-efficient numerical model is successfully validated under high-speed no-load operation, using a silicon-carbide based three-phase inverter. Rotors with four different magnet thicknesses in the range $3-12.6 \mathrm{~mm}$ are experimentally evaluated for frequencies in the range $8-120 \mathrm{kHz}$. The developed 3D model not only enables loss separation, but also prediction capability of harmonic losses within $15 \%$ over the whole frequency range. The conducted sensitivity analysis primarily emphasizes the importance of taking into account the axial segmentation of magnets, and secondarily the rotor-shaft magneto-elasticity effects for accurate modeling. Whereas 2D models overestimate losses with up to $240 \%$, the magneto-elasticity affects loss modeling with up to $30 \%$ at $10 \mathrm{kHz}$. The sensitivity analysis also indicates an almost complete demagnetization in the radial direction of the shaft $\left(1<\mu_{\text {r,shaft }}<2\right)$. However, it is found that the stator yoke polarization and magnet anisotropy have negligible impact on the modeling accuracy. The results validate the approach of harmonic superposition under no-load operation and show that rotor losses comprise $60-80 \%$ of the total harmonic losses. Furthermore, the conducted case study shows that harmonic losses can be reduced with two-thirds (from $27 \mathrm{~W}$ to $9 \mathrm{~W}$ ) by deploying thinner magnets and 40 (instead of 8) $\mathrm{kHz}$ switching frequency, thus enabling usage of significantly smaller motor filters. Future work includes development of analytical models, evaluation of inverter losses and electric drive optimization.

\section{REFERENCES}

[1] F. Luise, A. Tessarolo, F. Agnolet, S. Pieri, M. Scalabrin, M. Chiara, and M. Martin, "Design Optimization and Testing of High- Performance Motors," IEEE Ind. Appl. Mag., no. 6, pp. 19-32, 2016.

[2] N. Bianchi, S. Bolognani, and F. Luise, "Potentials and limits of high speed PM motors," IEEE Trans. Ind. Appl., vol. 3, no. 6, pp. 1570-1578, 2004.

[3] D. Gerada, A. Mebarki, N. L. Brown, C. Gerada, A. Cavagnino, and A. Boglietti, "High-Speed Electrical Machines: Technologies, Trends, and Developments," IEEE Trans. Ind. Electron., vol. 61, no. 6, pp. 29462959, 2014.

[4] O. Wallmark, P. Kjellqvist, and F. Meier, "Analysis of axial leakage in high-speed slotless PM motors for industrial hand tools," IEEE Trans. Ind. Appl., vol. 45, no. 5, pp. 1815-1820, 2009.

[5] T. Lipo and D. G. Holmes, Pulse Width Modulation for Power Converters, 1st ed. Wiley-IEEE Press, 2003.

[6] N. Bianchi, S. Bolognani, and F. Luise, "High Speed Drive Using a Slotless PM Motor,' IEEE Trans. Power Electron., vol. 21, no. 4, pp. 1083-1090, 2006.

[7] A. Borisavljevic, H. Polinder, and J. A. Ferreira, "On the Speed Limits of Permanent-Magnet Machines,' IEEE Trans. Ind. Electron., vol. 57, no. 1, pp. 220-227, 2010.

[8] P. Sergeant and A. V. D. Bossche, "Segmentation of Magnets to Reduce Losses in Permanent-Magnet Synchronous Machines," IEEE Trans. Magn., vol. 44, no. 11, pp. 4409-4412, 2008.

[9] W. Y. Huang, A. Bettayeb, R. Kaczmarek, and J. C. Vannier, "Optimization of magnet segmentation for reduction of eddy-current losses in permanent magnet synchronous machine," IEEE Trans. Energy Convers., vol. 25, no. 2, pp. 381-387, 2010.

[10] K. Yamazaki and Y. Fukushima, "Effect of eddy-current loss reduction by magnet segmentation in synchronous motors with concentrated windings," IEEE Trans. Ind. Appl., vol. 47, no. 2, pp. 779-788, 2011.

[11] G. Choi and T. M. Jahns, "Analysis and Design Recommendations to Mitigate Demagnetization Vulnerability in Surface PM Synchronous Machines," IEEE Trans. Ind. Appl., vol. 54, no. 2, pp. 1292-1301, 2018.

[12] J. Millan, P. Godignon, X. Perpina, A. Perez-Tomas, and J. Rebollo, “A Survey of Wide Bandgap Power Semiconductor Devices," IEEE Trans. Power Electron., vol. 29, no. 5, pp. 2155-2163, 2014.

[13] J. Millinger, O. Wallmark, and J. Soulard, "High-Frequency Characterization of Losses in Fully Assembled Stators of Slotless PM Motors," IEEE Trans. Ind. Appl., vol. 54, no. 3, pp. 2265-2275, 2018. 
[14] L. Schwager, A. Tuysuz, C. Zwyssig, and J. W. Kolar, "Modeling and comparison of machine and converter losses for PWM and PAM in highspeed drives," IEEE Trans. Ind. Appl., vol. 50, no. 2, pp. 995-1006, 2014.

[15] F. Dubas and A. Rahideh, "Two-Dimensional Analytical PermanentMagnet Eddy-Current Loss Calculations in Slotless PMSM Equipped With Surface-Inset Magnets," IEEE Trans. Magn., vol. 50, no. 3, pp. 54-73, 2014.

[16] M. Markovic and Y. Perriard, "Analytical Solution for Rotor EddyCurrent Losses in a Slotless Permanent-Magnet Motor: The Case of Current Sheet Excitation," IEEE Trans. Magn., vol. 44, no. 3, pp. $386-$ 393, Mar. 2008.

[17] M. R. Shah and S. B. Lee, "Rapid Analytical Optimization of EddyCurrent Shield Thickness for Associated Loss Minimization in Electrical Machines," IEEE Trans. Ind. Appl., vol. 42, no. 3, pp. 642-649, 2006.

[18] F. Deng, "Improved Analytical Modeling of Commutation Losses Including Space Harmonic Effects in Permanent Magnet Brushless DC Motors," in IEEE Ind. Appl. Conf., vol. 1, pp. 380-386, Oct. 1998.

[19] Z. Zhu, N. Schofield, and D. Howe, "Improved analytical modelling of rotor eddy current loss in brushless machines equipped with surfacemounted permanent magnets," Proc. IEE Electric Power Appl., vol. 151, no. 6, pp. 641-650, 2004.

[20] J. D. Ede, K. Atallah, G. W. Jewell, J. B. Wang, and D. Howe, "Effect of Axial Segmentation of Permanent Magnets on Rotor Loss in Modular Permanent-Magnet Brushless Machines," IEEE Trans. Ind. Appl., vol. 43, no. 5, pp. 1207-1213, 2007.

[21] S. Ruoho, T. Santa-Nokki, J. Kolehmainen, and A. Arkkio, "Modeling Magnet Length In 2-D Finite-Element Analysis of Electric Machines," IEEE Trans. Magn., vol. 45, no. 8, pp. 3114-3120, Aug. 2009.

[22] K. Yamazaki, M. Shina, Y. Kanou, M. Miwa, and J. Hagiwara, "Effect of Eddy Current Loss Reduction by Segmentation of Magnets in Synchronous Motors: Difference Between Interior and Surface Types," IEEE Trans. Magn., vol. 45, no. 10, pp. 4756-4759, 2009.

[23] M. Mirzaei, A. Binder, B. Funieru, and M. Susic, "Analytical Calculations of Induced Eddy Currents Losses in the Magnets of Surface Mounted PM Machines With Consideration of Circumferential and Axial Segmentation Effects," IEEE Trans. Magn., vol. 48, no. 12, pp. 48314841, 2012.

[24] S. T. Lundmark and P. R. Fard, "Two-Dimensional and ThreeDimensional Core and Magnet Loss Modeling in a Radial Flux and a Transverse Flux PM Traction Motor," IEEE Trans. Ind. Appl., vol. 53, no. 3, pp. 2028-2039, 2017.

[25] S. S. Nair, S. Member, J. Wang, S. Member, T. Sun, L. Chen, R. Chin, M. Beniakar, D. Svechkarenko, and I. Manolas, "Experimental Validation of 3-D Magnet Eddy Current Loss Prediction in Surface-Mounted Permanent Magnet Machines," vol. 53, no. 5, pp. 4380-4388, 2017.

[26] D. Roger, E. Napieralska-Juszczak, and A. Henneton, "High Frequency Extension of Non-Linear Models of Laminated Cores," Int. J. Comput. Math. Electr. Electron. Eng., vol. 26, no. 4, pp. 986-1004, 2006.

[27] O. Bottesi, L. Alberti, R. V. Sabariego, and J. Gyselinck, "Finite Element Small-Signal Simulation of Electromagnetic Devices Considering Eddy Currents in the Laminations," IEEE Trans. Magn., vol. 53, no. 5, 2017.

[28] T. D. Batzel and K. Y. Lee, "Slotless Permanent Magnet Synchronous Motor Operation Without a High Resolution Rotor Angle Sensor,' IEEE Trans. Energy Convers., vol. 15, no. 4, pp. 366-371, 2000.

[29] Published data sheets from Cogent Power, 2017. [Online]. Available: https://cogent-power.com/downloads

[30] R. Brandt and G. Neuer, "Measurement of the Electric Resistivity of Metals up to and Above the Melting Temperature," Advanced Engineering Materials, vol. 5, no. 1, pp. 52-55, 2003.

[31] N. Bernard, F. Martin, and M. E. Zaïm, "Design Methodology of a Permanent Magnet Synchronous Machine for a Screwdriver Application," IEEE Trans. Energy Convers., vol. 27, no. 3, pp. 624-633, 2012.

[32] J. Millinger and J. Soulard, "Energy-Efficiency of Electrical Machine and Drive with SiC Transistors (2015-03073)," Tech. Rep., 2016. [Online]. Available: urn:nbn:se:kth:diva-212295

[33] M. K. Kazimierczuk, High-Frequency Magnetic Components, 2nd ed. Wiley Interscience, 2014.

[34] P. Brauer, "High-Frequency Voltage Distribution Modelling of a Slotless PMSM from a Machine Design Perspective," M.S thesis, KTH Royal Institute of Technology, 2015.

[35] J. Millinger, J. Soulard, and O. Wallmark, "Influence of Shaft Relative Permeability on Rotor Losses in 2-pole Slotless High-Speed Motor," in Proc. XXII Int. Conf. Electr. Mach., pp. 407-413, Lausanne, Switzerland, 2016.
[36] J. A. Walker, D. G. Dorrell, and C. Cossar, "Flux-Linkage Calculation in Permanent-Magnet Motors Using the Frozen Permeabilities Method," IEEE Trans. Magn., vol. 41, no. 10, pp. 3946-3948, 2005.

[37] A. Belahcen, "Magnetoelasticity, Magnetic Forces and Magnetostriction in Electrical Machines," Ph.D. dissertation, Helsinki University of Technology, 2004

[38] M. J. Sablik, S. W. Rubin, L. A. Riley, D. C. Jiles, D. A. Kaminski, and S. B. Biner, "A model for hysteretic magnetic properties under the application of noncoaxial stress and field," J. Appl. Phys., vol. 74, no. 1, pp. $480-488,1993$

[39] F. Deng, "Commutation-Caused Eddy-Current Losses in PermanentMagnet Brushless DC Motors," IEEE Trans. Magn., vol. 33, no. 5, pp. 4310-4318, 1997

[40] M. Markovic and Y. Perriard, "An Analytical Determination of EddyCurrent Losses in a Configuration With a Rotating Permanent Magnet," IEEE Trans. Magn., vol. 43, no. 8, pp. 3380-3386, Aug. 2007.

[41] M. Katter and S. Gromotka, "Angular dependence of the demagnetization stability of VACODYM magnets," Vacuumschmelze Investig. Rep., no. UB-DM/912, 2004.

[42] D. Benedikt, "Spezifischer elektrischer Widerstand VD," Vacuumschmelze Tech. Notiz, no. TN-DM 1210, 2012.

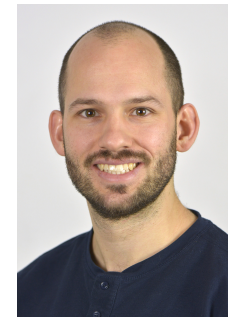

Jonas Millinger ( $\left.S^{\prime} 16\right)$, born in Stockholm Sweden received the M.Sc. degree in electrical engineering from the KTH Royal Institute of Technology, Stockholm, Sweden, in 2011, where he is currently working toward the Ph.D. degree in Electrical Engineering with the Department of Electric Power and Energy Systems. Since 2010, he has been with Atlas Copco, Stockholm, where he is involved in the design of electrical machines for power tools. His research interests include modeling and design of electrical machines, with a current focus on harmonic losses and motordrive system optimization.

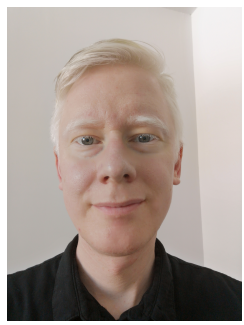

Oskar Wallmark (S'01-M'06-SM'18), born in 1976, Sweden, received his M.Sc. in Engineering Physics in 2001 and his Ph.D. in Electric Power Engineering in 2006, both from Chalmers University of Technology, Göteborg, Sweden. In 2015, he received the Docent degree from KTH Royal Institute of Technology. Currently, he holds the position as an Associate Professor at the Department of Electric Power and Energy Systems. His main research interests include control and analysis of electric drives with particular focus on automotive applications.

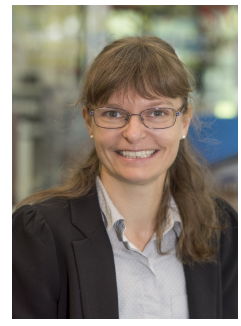

Juliette Soulard (M'00) received the Ph.D. de gree in Electrical Engineering from the University of Paris VI, France, in 1998. At the time this study, she was Associate Professor with the Department of Electric Power and Energy Systems, leading the Electrical Machines and Drives laboratory at KTH Royal Institute of Technology, Stockholm, Sweden. Since September 2016, she is associate professor at the International Automotive Research Center, within WMG, University of Warwick, United Kingdom. Her research interests include modelling and design of electrical machines, especially losses, manufacturing effects and thermal modelling. 